\title{
E D I T O R I A L
}

\section{London}

August 1953

\section{Training for General Practice}

Most medical students become general practitioners but the curriculum does not take sufficient account of this obvious fact. In a recent number of the British Medical Fournal eight practitioners who form the Undergraduate Education Committee of the Foundation Council of the College of General Practitioners have reported on the teaching of general practice in our undergraduate medical schools. Those who teach our students will find this report both interesting and challenging.

The science and practice of medicine as seen in hospital must form the basis of clinical teaching, but the curriculum should go beyond this. It has been estimated that a doctor has to be in general practice for three years before he sees a patient with a carcinoma of the breast, 24 years before he sees a primary tumour of bone and ro6 years a tumour of the testicle. In other words, assuming the average working life of a general practitioner to be 35 years, only one practitioner in three will see a tumour of the testicle in his own consulting room and few will see more than one patient with a primary tumour of bone. Most medical schools devote at least one lecture and one tutorial to each of these subjects and the final examination commonly requires a candidate to write a question on them. The time spent on this type of teaching could be reduced without loss to anybody; in its place certain aspects of general practice could be stressed. In order to bring due emphasis to bear on this point the final examination should contain more questions with a slant towards the home care of the patient. One university recently had the following question in the surgery paper: 'A butcher of 50 has been given a colostomy following the removal of a carcinoma of the rectum. What advice would you give to (a) the patient and (b) his wife?' An answer to this question should reveal the candidate's knowledge of practical surgery, certain aspects of public health and, above all, how he would look after his patients in their homes.

The home care of patients was taught to the medical apprentice by his master. Since the abandonment of this system the science and practice of medicine has been taught in our medical schools and few would deny that this change has not raised the standard of medical knowledge and practice. Unfortunately the student in mosi medical schools now waits until he enters practice before he sees how patients should be looked aftê일 in their homes. Some are the sons of general practitioners and they may learn from their parents; most of the others pick up the principles of home care during their first few years in practice. Some instruction during the undergraduate course would help them to bridge this gap between the patient in hospital and the patient at home.

The College of General Practitioners suggests that general practitioners should take part in undergraduate teaching both as teachers and as advisers to the Deans on what subjects should be taught. Only good would come from such an arrangement. In particular the curriculum could be modified. We are told that one of the commonest complaints in general practice is of insomnia. How many schools include a lecture on this subject in their undergraduate course? But perhaps the most important lesson which has to be learnt during the transition period from student to practitioner is how to recognize at any early $\overparen{D}$ stage the existence of those characteristics which distinguish a serious or potentially serious disease from a minor ailment. 